\title{
Características da carcaça e dos componentes não-carcaça de ovinos alimentados com dietas contendo casca de mamona
}

\author{
Carcass characteristics and non-carcass components of lambs fed with diets containing \\ castor bean hulls
}

\author{
POMPEU, Roberto Cláudio Fernandes Franco ${ }^{1}$; BESERRA, Liandro Torres ${ }^{2}$; \\ CÂNDIDO, Magno José Duarte ${ }^{3}$; BOMFIM, Marco Aurélio Delmondes ${ }^{1}$; VIEIRA, \\ Marieta Maria Martins ${ }^{4}$; ANDRADE, Ricardo Rodrigues de ${ }^{5}$
}

\author{
${ }^{1}$ Embrapa Caprinos e Ovinos, Sobral, Ceará, Brasil. \\ ${ }^{2}$ Instituto Federal de Educação, Ciência e Tecnologia, Xapuri, Acre, Brasil. \\ ${ }^{3}$ Universidade Federal do Ceará, Campus do Pici, Departamento de Zootecnia, Fortaleza, Ceará, Brasil. \\ ${ }^{4}$ Instituto Federal de Educação, Ciência e Tecnologia, Umirim, Ceará, Brasil. \\ ${ }^{5}$ Instituto Federal de Educação, Ciência e Tecnologia, Tauá, Ceará, Brasil. \\ *Endereço para correspondência: roberto.pompeu@embrapa.br
}

\section{RESUMO}

Objetivou-se avaliar a influência de quatro níveis de substituição $(0 ; 33 ; 67$ e 100$)$ do feno de capim-tifton 85 (FT) pela casca de mamona (CM) em rações sobre as características quantitativas da carcaça e dos componentes nãocarcaça de ovinos mestiços de Morada Nova, com peso corporal médio de $20,3 \mathrm{~kg}$ e idade média de 6,5 meses num delineamento inteiramente casualizado com cinco repetições. Foram avaliados o peso, o rendimento, a composição regional das carcaças e os componentes não-carcaças. Observou-se efeito linear decrescente dos níveis de substituição do FT pela CM sobre o peso corporal, peso corporal ao abate em jejum, peso do corpo vazio, peso de carcaça quente e fria, assim como os rendimentos de carcaças quente e fria. Os níveis de substituição do FT pela CM apresentaram influência negativa sobre o peso dos cortes à medida que se adicionou $\mathrm{CM}$ na dieta dos animais, enquanto a área de olho-delombo e a espessura de gordura subcutânea não apresentaram efeito. O rendimento do lombo posterior foi influenciado de forma linear decrescente pelos níveis de substituição do FT pela $\mathrm{CM}$, enquanto os rendimentos das demais regiões não apresentaram efeito dos níveis de substituição. Observou-se efeito dos níveis de substituição do FT pela CM para maioria dos componentes não-carcaça, com exceção da vesícula biliar, bexiga, nódulos, abomaso, intestino delgado e gordura do coração. A casca de mamona acima de $33 \%$ em substituição ao feno de tifton-85 na dieta para ovinos influencia negativamente as características das carcaças e os componentes não-carcaça.

Palavras-chave: borregos, composição regional da carcaça, Ricinus communis, subprodutos do biodiesel

\section{SUMMARY}

This study was undertaken to evaluate the influence of four substitution levels $(0 ; 33 ; 67$ and $100 \%$ ) of Tifton 85 hay (TH) by castor bean hulls $(\mathrm{CH})$ on carcass characteristics and non carcass components in Morada Nova crossbred lambs, with $20.3 \mathrm{~kg}$ body weight and 6.5 months old. A completely randomized design with four treatments and five replicates (lambs) was used. It was evaluated the carcass weight, the carcass yield, the relative composition of the commercial cuts and the non carcass components. There were negative linear effect of the substitution levels of $\mathrm{TH}$ by $\mathrm{CH}$ on final body weight, live weight with fasting, empty body weight, hot carcass weight and cold carcass weight, as well as hot carcass yield and cold carcass yield. The substitution levels of TH by $\mathrm{CH}$ presented negative influence on the commercial cuts when was added castor bean hulls on lambs diets, while there is not effect of 
the substitution levels of TH by $\mathrm{CH}$ on loin eye area and fat thickness. There is negative linear effect of the substitution of $\mathrm{TH}$ by $\mathrm{CH}$ on back loin yield, while the others commercial cuts were not influenced. There were effects of the substitution of $\mathrm{TH}$ by $\mathrm{CH}$ to the majority non carcass components, with exception to the gall bladder, bladder, nodule, abomasum, small intestine and fat from the heart. The castor bean hulls over $33 \%$ in substitution to the Tifton 85 hay in diets to the sheep influence negatively the carcass characteristics and the non carcass components.

Keywords: biodiesel byproducts, lambs, relative composition of the commercial cuts, Ricinus communis

\section{INTRODUÇÃO}

No Semiárido Brasileiro, a pastagem nativa da Caatinga é a principal fonte de alimento para os rebanhos de ovinos desta região. Devido à má distribuição das chuvas, geralmente concentradas em 3 a 4 meses do ano, os rebanhos tornam-se bastante vulneráveis à estacionalidade da produção de forragem, deixando os produtores locais sem muitas alternativas alimentares, passando a produção de alimentos a ser um dos maiores desafios durante os meses de estiagem. Nesse contexto, a disponibilidade de subprodutos de baixo custo tem despertado o interesse de pesquisadores, no sentido de viabilizar uma exploração mais racional na alimentação desses animais.

No Nordeste, a produção de biodiesel de mamona surgiu há pouco tempo como uma promissora alternativa para os pequenos produtores da região, sendo a cultura da mamona a principal oleaginosa para a produção de biodiesel por ser de fácil cultivo, de baixo custo e pela sua resistência à seca. Entre os subprodutos do beneficiamento, a casca de mamona representa, em média, 25\% do peso do fruto, sendo os $75 \%$ restantes correspondendo ao peso total das sementes (baga). Embora a região Nordeste detenha uma produtividade baixa de mamona (600 kg/ha), a produção de casca pode atingir $261 \mathrm{mil}$ toneladas por ano (SEVERINO et al., 2005).

Segundo Santos et al. (2011), a casca de mamona é um alimento volumoso apresentando $72 \%$ de FDN, mas sua composição é bastante variada, principalmente em função da participação de fragmentos de sementes, que pode chegar a $15 \%$, podendo trazer risco de intoxicação pela presença da ricina devido aos fragmentos de amêndoa. $\mathrm{O}$ teor de proteína bruta da casca de mamona pode variar entre 5 e $8 \%$. A inclusão da casca de mamona em substituição ao feno de capim-tifton 85 na dieta de cabras em lactação nos níveis de $0 ; 33 ; 67$ e 100\% reduziu o consumo de matéria seca e a produção de leite provavelmente devido à influência negativa do teor de fibra sobre a digestibilidade (SANTOS et al., 2011). Relatos sobre utilização da casca de mamona na alimentação de ruminantes são escassos na literatura e representa uma demanda real da cadeia produtiva.

Diante do exposto, este trabalho foi conduzido com o objetivo de avaliar o efeito da substituição do feno de capimtifton 85 pela casca de mamona em dietas para ovinos confinados sobre as características quantitativas da carcaça, dos componentes não-carcaça e rendimento dos cortes comerciais.

\section{MATERIAL E MÉTODOS}

O trabalho foi conduzido no Núcleo de Ensino e Estudos em Forragicultura do Departamento de Zootecnia do Centro de Ciências Agrárias da Universidade 
Federal do Ceará -

NEEF/DZ/CCA/UFC

(www.neef.ufc.br) em Fortaleza, Ceará. O município de Fortaleza situa-se na zona litorânea a $15,49 \mathrm{~m}$ de altitude, $30^{\circ} 43^{\prime} 02^{\prime \prime}$ de latitude sul, e $38^{\circ} 32^{\prime} 35^{\prime \prime}$ de longitude oeste.

Foram avaliados quatro níveis de substituição $(0 ; 33 ; 67$ e $100 \%)$ do feno de capim-tifton 85 pela casca de mamona, num delineamento inteiramente casualizado com cinco repetições (ovinos).

A casca de mamona foi fornecida pela empresa Brasil Ecodiesel Indústria e Comércio de Biocombustíveis, localizada no município de Crateús-CE e o feno de capim-tifton 85 foi comprado em comércio local.

As unidades experimentais constaram de ovinos mestiços ( $1 / 2$ Morada Nova var. vermelha $\mathrm{x} \quad 1 / 2$ sem padrão racial definido), machos, não castrados, com peso vivo inicial de $20,3 \pm 2,5 \mathrm{~kg}$ e idade aproximada de 6,5 meses. Antes do início do experimento, os animais foram vermifugados e receberam suplementação de vitaminas A, D e E injetável por via subcutânea.

As rações concentradas tinham como ingredientes farelo de soja, milho, uréia, fosfato bicálcico, calcário calcítico, enxofre sublimado (flor de enxofre) e inerte (areia lavada) em todos os tratamentos (Tabela 1). A utilização do inerte visou garantir que as dietas experimentais fossem isoenergéticas, diluindo os níveis de energia nas dietas com maiores níveis de casca, não comprometendo, portanto o consumo e a digestão de alimentos pelos animais. Esses níveis de inerte estão dentro dos níveis de consumo de solo por ovinos em pastejo, que estão em torno de 10 a $40 \%$ MS (ABRAHAMS \& STEIGMAJER, 2003).

Tabela 1. Percentagem de ingredientes das rações de ovinos confinados recebendo diferentes níveis de substituição do feno de capim-tifton 85 pela casca de mamona

\begin{tabular}{|c|c|c|c|c|}
\hline \multirow{2}{*}{ Ingrediente } & \multicolumn{4}{|c|}{ Nível de substituição (\% da matéria seca do feno) } \\
\hline & 0 & 33 & 67 & 100 \\
\hline Feno de capim-tifton 85 & 49,67 & 32,78 & 16,89 & 0,00 \\
\hline Casca de mamona & 0,00 & 16,89 & 32,78 & 49,67 \\
\hline Farelo de soja & 1,67 & 3,62 & 5,54 & 7,59 \\
\hline Milho & 46,57 & 40,56 & 34,49 & 28,05 \\
\hline Uréia & 0,80 & 0,80 & 0,80 & 0,80 \\
\hline Fosfato Bicálcico & 0,55 & 0,14 & 0,00 & 0,00 \\
\hline Calcário calcítico & 0,64 & 0,85 & 1,06 & 1,48 \\
\hline Enxofre sublimado $^{1}$ & 0,09 & 0,09 & 0,09 & 0,09 \\
\hline Inerte & 0,00 & 4,27 & 8,35 & 12,33 \\
\hline
\end{tabular}

${ }^{1}$ Flor de enxofre.

As rações foram balanceadas para serem isoprotéicas e isoenergéticas, com relação volumoso:concentrado de 50:50 em todos os tratamentos de modo a perfazerem um teor de proteína bruta de $12,3 \%$ e de energia metabolizável de
2,4Mcal/kg (Tabela 2), suficientes para ganhos de $150 \mathrm{~g} /$ ovino $\mathrm{x}$ dia, em se tratando de animais mestiços de Morada Nova, conforme Gonzaga Neto et al. (2005). A casca de mamona utilizada no experimento apresentava $6 \%$ de 
fragmentos de sementes, o que conferiu a este alimento fibroso e energético.

\section{Tabela 2. Composição químico- bromatológica da casca de mamona e do feno de capim- tifton 85 utilizados nas dietas experimentais}

\begin{tabular}{lcc}
\hline & \multicolumn{2}{c}{ Volumoso } \\
\cline { 2 - 3 } Item (\%) & $\begin{array}{c}\text { Casca de } \\
\text { mamona }\end{array}$ & $\begin{array}{c}\text { Feno de capim- } \\
\text { tifton } 85\end{array}$ \\
\hline MS & 97,05 & 93,56 \\
PB & 10,48 & 6,19 \\
MM & 12,32 & 6,78 \\
EE & 12,92 & 2,37 \\
FDN & 58,59 & 80,66 \\
PIDN & 3,03 & 4,09 \\
FDNcp & 52,43 & 76,62 \\
FDA & 44,87 & 43,54 \\
PIDA & 2,83 & 1,73 \\
CEL & 28,09 & 35,63 \\
LIG & 2,88 & 4,91 \\
HC & 14,11 & 37,11 \\
\hline
\end{tabular}

$\mathrm{MS}=$ matéria seca; $\mathrm{PB}=$ proteína bruta; $\mathrm{MM}=$ matéria mineral; $\mathrm{EE}=$ estrato etéreo; $\mathrm{FDN}=$ fibra insolúvel em detergente neutro; CIDN = cinzas do FDN; PIDN = nitrogênio insolúvel em detergente neutro: FDNcp = fibra insolúvel em detergente neutro corrigido para cinzas e proteína; FDA = fibra insolúvel em detergente ácido; $\mathrm{CEL}=$ celulose $; \mathrm{LIG}=$ lignina; $\mathrm{PIDA}=$ nitrogênio insolúvel em detergente ácido; $\mathrm{HC}=$ hemicelulose.

A ração experimental foi fornecida diariamente em duas refeições, às $8 \mathrm{~h}$ ( $50 \%$ do total ofertado ao dia) e outra às $14 \mathrm{~h}(50 \%$ do total ofertado ao dia), coletando-se no dia seguinte as sobras, que foram pesadas, mantendo-as em torno de $15 \%$. O sal mineral era fornecido diariamente em média de $17,5 \mathrm{~g} /$ ovino $\mathrm{x}$ dia, segundo recomendações de Girão (1997).

Os animais foram confinados em baias individuais de madeira, providas de comedouros e bebedouros e pesados semanalmente durante todo o período experimental, que consistiu de 14 dias de adaptação e 56 dias de coleta. Amostragens dos alimentos fornecidos e das sobras foram realizadas diariamente pela manhã no momento da pesagem do alimento que cada animal recebeu durante todo o período de coleta dos dados. As amostras foram acondicionadas em sacos plásticos identificados e armazenadas a $10^{\circ} \mathrm{C}$. Ao final do experimento, as amostras referentes a cada animal, foram descongeladas e homogeneizadas, sendo retirada uma amostra de, aproximadamente, $300 \mathrm{~g}$, que foi levada ao Laboratório de Nutrição Animal da Universidade Federal do Ceará, pesada e colocada em estufa de ventilação forçada por três dias sob temperatura de $60 \pm 5^{\circ} \mathrm{C}$ (Tabela 3). Posteriormente, as mesmas foram moídas em moinho tipo "Wiley", com peneira de 30 "mesh", acondicionadas em potes de plástico. Para as determinações da matéria seca (MS), extrato etéreo (EE) e proteína bruta (PB) dos alimentos e sobras, seguiram-se as metodologias propostas pela AOAC (1995). A quantificação da fibra em detergente neutro (FDN) utilizou-se a metodologia proposta por Van Soest et al. (1991). A energia metabolizável das dietas experimentais foi estimada segundo Agricultural Food Research Council (AFRC, 1993).

No final do período experimental (70 dias) os animais tiveram seu peso corporal final registrado antes e depois de serem submetidos a jejum de dieta sólida por 18 horas. No momento do abate, os animais foram insensibilizados por atordoamento na região atlantooccipital, seguido por sangria durante três minutos, seccionando-se as veias jugulares e as artérias carótidas para recolhimento do sangue em balde previamente pesado (tara), para posteriores pesagem e identificação.

Após o abate, realizou-se a esfola, evisceração, retirada da cabeça, patas e 
órgãos genitais. Sequencialmente, as carcaças foram pesadas para a obtenção do peso da carcaça quente (PCQ). Em seguida, foram envolvidas por sacos plásticos identificados por animal/tratamento e transportadas para câmara frigorífica a $4^{\circ} \mathrm{C}$, onde permaneceram por 24 horas, sendo novamente pesadas para a obtenção do peso da carcaça fria (PCF). $\mathrm{O}$ trato gastrintestinal foi esvaziado e pesado antes e depois do procedimento para obtenção do peso corporal vazio (PCV
$=$ PCQ - conteúdo gastrintestinal), visando determinar $\mathrm{o}$ rendimento verdadeiro ou biológico (RB), obtido pela relação entre o peso da carcaça quente e o peso corporal vazio. Para a determinação do rendimento de carcaça quente (RCQ), rendimento de carcaça fria $(\mathrm{RCF})$ e rendimento biológico (RB) foram utilizadas as fórmulas que seguem: $\mathrm{RCQ}=(\mathrm{PCQ} / \mathrm{PVAJ}) \times 100$; $\mathrm{RCF}=(\mathrm{PCF} / \mathrm{PVAJ}) \times 100 ; \mathrm{RB}=$ (PCQ/PCVZ) X 100, respectivamente (SILVA SOBRINHO, 2001).

Tabela 3. Composição químico-bromatológica das dietas de ovinos confinados alimentados com diferentes níveis de substituição do feno de capim-tifton 85 pela casca de mamona

\begin{tabular}{cccccccc}
\hline \multirow{2}{*}{ Nível de substituição (\%) } & MS & PB & FDN & Ca & P & EE & EM \\
\cline { 2 - 7 } & \% MN & \%MS & \%MS & \%MS & $\% \mathrm{MS}$ & $\% \mathrm{MS}$ & $(\mathrm{Mcal} / \mathrm{kg})$ \\
\hline 0 & 89,35 & 12,27 & 42,45 & 0,63 & 0,31 & 4,25 & 2,35 \\
33 & 90,01 & 12,27 & 40,62 & 0,63 & 0,31 & 5,33 & 2,36 \\
67 & 90,67 & 12,27 & 38,90 & 0,69 & 0,36 & 6,32 & 2,36 \\
100 & 91,36 & 12,27 & 37,07 & 0,87 & 0,43 & 7,37 & 2,36 \\
\hline
\end{tabular}

Todos os componentes não-carcaça foram separados e pesados, quais sejam: sangue, pele, cabeça, rúmen, retículo, omaso, abomaso, intestino delgado, intestino grosso, baço, fígado, coração, pâncreas, rins, gorduras perirrenal, omental (recobre os estômagos) e mesentérica (recobre os intestinos), patas, nódulos e sistema reprodutor. De acordo com Mattos et al. (2006), os componentes não-carcaça são definidos como os constituintes do peso do corpo vazio, com exceção da carcaça, ou seja, o conjunto de órgãos, vísceras e outros subprodutos obtidos após o abate dos animais.

Para a obtenção dos cortes, a carcaça foi dividida após a retirada do pescoço, em duas partes simétricas através de corte longitudinal da coluna vertebral. A meia carcaça esquerda foi dividida em seis regiões anatômicas denominadas cortes comerciais, sendo eles: perna, lombo (anterior e posterior), paleta, peito, costela e fraldinha (MONTE et al., 2009). O lombo foi dividido em anterior e posterior, considerando que esses cortes são comercializados separadamente. Em seguida os cortes foram pesados e foram feitas determinações das porcentagens em relação à carcaça inteira. Os limites anatômicos entre os cortes foram efetuados conforme o descrito por Gatty (1986). A perna e o lombo (anterior e posterior) foram considerados cortes de primeira categoria, a paleta como de segunda e os demais cortes de terceira categoria, seguindo o sistema de classificação dos cortes adotado por Yamamoto et al. (2004); Frescura et al. (2005) e Monte et al. (2009).

Foi determinada a área de olho-delombo realizada a partir de um corte transversal entre a $12^{\mathrm{a}}$ e a $13^{\mathrm{a}}$ vértebras 
torácicas, efetuando-se em transparência plástica o desenho da área, em correspondência à porção cranial do lombo estabelecendo-se a largura e a profundidade máxima para o cálculo da área de olho-de-lombo (AOL), conforme sugerido por Silva Sobrinho (1999), a partir da seguinte fórmula $\mathrm{AOL}=(\mathrm{A} / 2 \times \mathrm{B} / 2) \pi$, em que: $\mathrm{A}=$ largura e $\mathrm{B}=$ profundidade. Também foi determinada a espessura da gordura subcutânea (EGS), que é a espessura máxima de gordura de cobertura sobre a superfície da $13^{\mathrm{a}}$ costela, a $11 \mathrm{~cm}$ da linha dorso-lombar, com auxílio do paquímetro.

Os dados foram analisados por meio de análise de variância e de análise de regressão $(\mathrm{P}<0,05)$. A escolha dos modelos baseou-se na significância dos coeficientes linear ou quadrático, utilizando-se o teste " $\mathrm{t}$ ", de Student, ao nível de $5 \%$ de probabilidade, e no coeficiente de determinação. Como ferramenta de auxílio às análises estatísticas, utilizou-se o procedimento GLM do programa estatístico SAS (SAS Institute, 2003).

\section{RESULTADOS E DISCUSSÃO}

Observou-se efeito linear decrescente $(\mathrm{P}<0,05)$ dos níveis de substituição do feno de capim-tifton 85 (FT) pela casca de mamona (CM) sobre o peso corporal (PC) e peso corporal ao abate em jejum (PCVJ), devido à redução do consumo de nutrientes, já que o desempenho animal é função da ingestão de nutrientes e, este por sua vez, é determinado pela quantidade de matéria seca ingerida (Figura 1). Para cada 1\% de substituição do FT pela $\mathrm{CM}$, estimou-se decréscimos de $0,09 \mathrm{~kg}$ no peso corporal sem jejum e peso corporal ao abate em jejum.

Apesar de todos os animais terem tido o mesmo período de confinamento (70 dias), o menor peso ao abate dos ovinos alimentados com maiores níveis de casca de mamona na dieta deveu-se ao fato desta possuir uma estrutura com maior grau de dificuldade para ingestão e menor palatabilidade em relação ao feno de capim-tifton 85. A maior quantidade de fragmentos de semente de mamona $(15 \%)$ na casca também pode ter repercutido na elevação da quantidade de extrato etéreo na dieta e consequentemente na proporção de ácido ricinoléico, que representa mais de $90 \%$ do total de ácido graxo da torta de mamona (MOSHKIN, 1986). Assim, é possível que a hidroxila presente no carbono 12 do ácido ricinoléico afete negativamente $\mathrm{o}$ metabolismo microbiano (OLIVEIRA et al., 2010), o que pode ter repercutido na redução da sua aceitabilidade, induzindo os animais a rejeitarem o volumoso nos maiores níveis de substituição.

$\mathrm{O}$ peso do corpo vazio (PCVZ) e os pesos de carcaça quente (PCQ) e de carcaça fria (PCF) reduziram-se linearmente $(\mathrm{P}<0,05)$ à medida que aumentou a casca de mamona (CM) na dieta dos ovinos. O peso ótimo de abate, principalmente de ovinos deslanados deve ser definido para cada raça, considerando a preferência dos consumidores. Zapata et al. (2001) reportaram que o peso de abate na região Nordeste tem sido próximo dos $30 \mathrm{~kg}$, que resulta em carcaça com 12,5 a $14,0 \mathrm{~kg}$. Dessa forma, estima-se que somente os ovinos alimentados com até $43 \%$ de substituição do FT pela CM estão dentro da faixa relatada pelos autores. 
Rev. Bras. Saúde Prod. Anim., Salvador, v.14, n.3, p.490-507 jul./set., 2013 http://www.rbspa.ufba.br ISSN 15199940

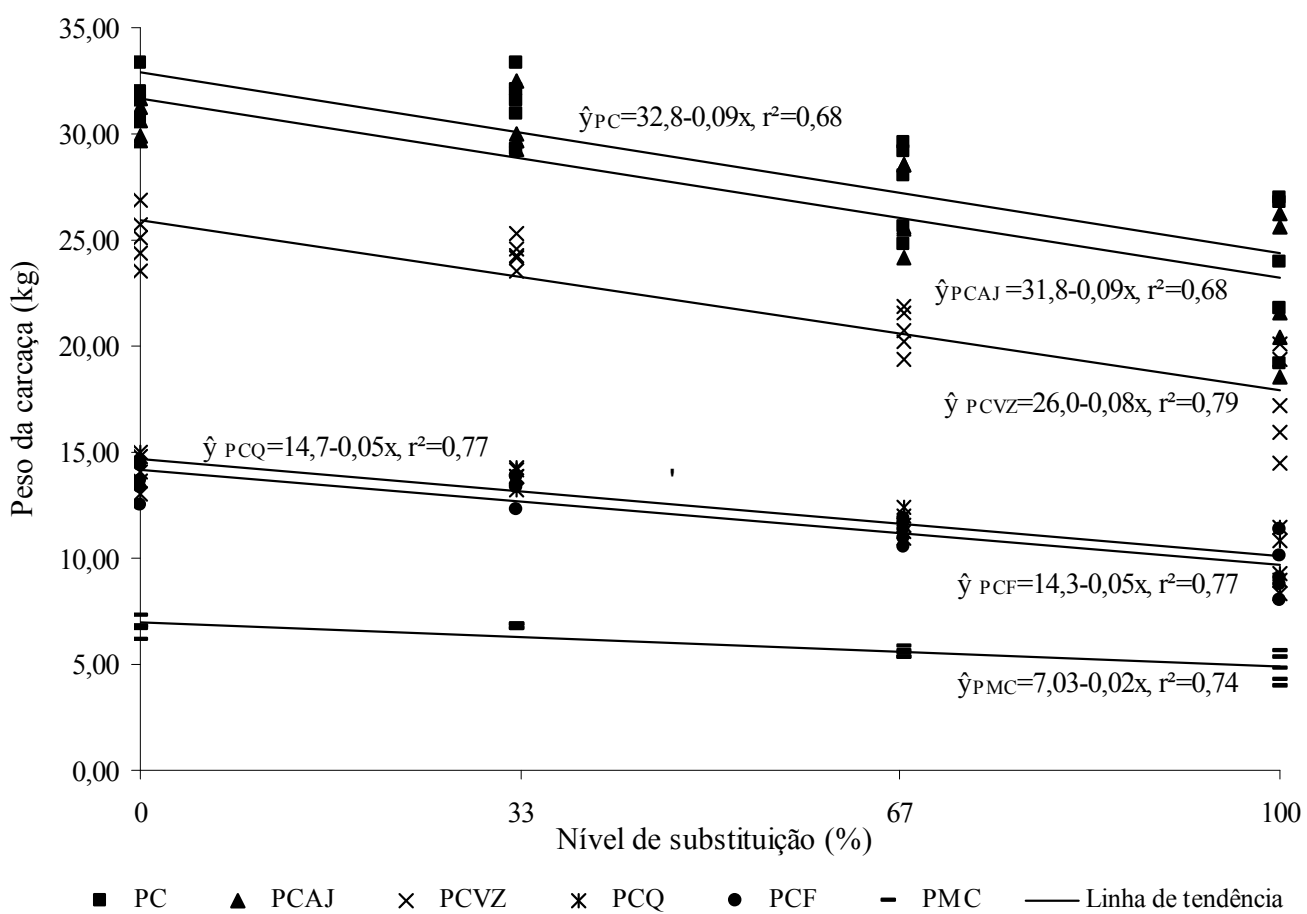

$\mathrm{PC}=$ peso corporal sem jejum $(\mathrm{kg}), \mathrm{PCAJ}=$ peso corporal ao abate em jejum $(\mathrm{kg})$, $\mathrm{PCVZ}=$ peso de corpo vazio $(\mathrm{kg}), \mathrm{PCQ}=$ peso da carcaça quente $(\mathrm{kg}), \mathrm{PCF}=$ peso da carcaça fria $(\mathrm{kg}), \mathrm{PMC}=$ peso da meia carcaça $(\mathrm{kg})$.

Figura 1. Efeito dos níveis de substituição do feno de tifton-85 pela casca de mamona sobre o peso de carcaça de ovinos. $\hat{y}=$ valores estimados a partir da equação de regressão para cada variável analisada; significativo ao nível de $5 \%$ (*) de probabilidade

O rendimento de carcaça quente (RCQ) foi afetado pelos níveis de substituição, apresentando resposta linear decrescente $(\mathrm{P}<0,05)$ com estimativas de 46,4 e $43,4 \%$ para 0 e $100 \%$ de substituição do feno de capimtifton 85 (FT) pela casca de mamona (CM), respectivamente (Figura 2), sendo semelhantes valores de RCQ relatados por Vieira et al. (2010), ao trabalharem com ovinos mestiços de Morada Nova alimentados com quatro níveis de substituição do farelo de soja pelo farelo de mamona destoxificado, os quais variaram entre 42,16 e $45,10 \%$. O mesmo comportamento foi observado para o rendimento de carcaça fria (RCF), onde para cada $1 \%$ de substituição do FT pela CM, observouse redução de 0,03 pontos percentuais. Observa-se que os ovinos alimentados com dietas contendo até $33 \%$ de casca de mamona em substituição ao feno de capim-tifton 85 apresentaram RCQ e RCF superiores aos preconizados por Silva Sobrinho (2001), que descreveu como rendimento de carcaça quente de $46 \%$ e fria de $44,5 \%$. Ainda, de acordo com Silva \& Pires (2000), os maiores rendimentos das carcaças ovinas são encontrados para os animais mais jovens, devido ao aumento do trato gastrintestinal com o avançar da idade, que diminui o rendimento das carcaças (SANTOS, et al., 2009; MORENO et al., 2010). 


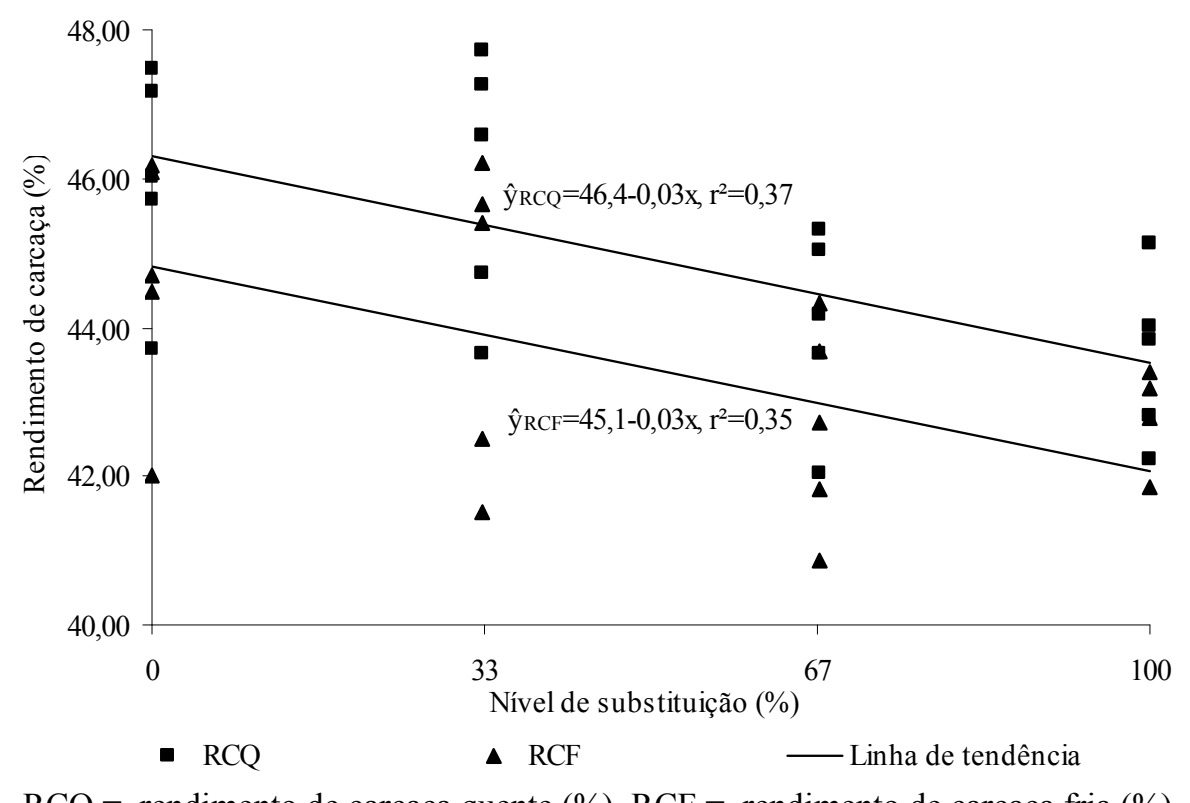

$\mathrm{RCQ}=$ rendimento de carcaça quente $(\%), \mathrm{RCF}=$ rendimento de carcaça fria $(\%)$

Figura 2. Efeito dos níveis de substituição do feno de tifton-85 pela casca de mamona sobre o rendimento de carcaça de ovinos. $\hat{y}=$ valores estimados a partir da equação de regressão para cada variável analisada; significativo ao nível de $5 \%(*)$ de probabilidade

O rendimento biológico $(\mathrm{RB})$ e a perda por resfriamento (PR) não foram influenciados $(\mathrm{P}>0,05)$ pelos diferentes níveis de casca de mamona na dieta dos ovinos e apresentaram médias de 56,3 e $2,90 \%$ respectivamente. A ausência de efeito para a perda por resfriamento pode ter ocorrido em função de fatores como a baixa cobertura de gordura das carcaças e a velocidade do ar da câmara fria. De acordo com Garcia (1998), em ovinos, de forma geral, os índices de perda por resfriamento estão na faixa entre 2 e $3 \%$, dentro do obtido no presente trabalho, no entanto pode ocorrer oscilações de acordo com a uniformidade da cobertura de gordura, o sexo, o peso, a temperatura e a umidade relativa da câmara fria. Portanto, quanto menor o percentual de PR, maior é a probabilidade de a carcaça ter sido manejada e armazenada de forma adequada.
Os níveis de substituição do feno de capim-tifton 85 pela casca de mamona apresentaram influência $(\mathrm{P}<0,05)$ sobre o peso dos cortes, sendo verificada redução à medida que se adicionou $\mathrm{CM}$ na dieta dos animais (Figuras 3 e 4). Tal resultado é decorrente da diminuição do peso corporal, assim como dos pesos de carcaça quente e fria e do peso da meia carcaça fria resultando em cortes menos pesados, sendo os principais fatores que contribuíram para redução do peso dos cortes comerciais.

A espessura de gordura subcutânea (EGS) e a área de olho-de-lombo (AOL) não apresentaram efeito $(\mathrm{P}>0,05)$ com a elevação da casca de mamona na dieta dos animais, com médias de $2,1 \mathrm{~mm}$ e $12,8 \mathrm{~cm}^{2}$, respectivamente. Tal resultado era esperado já que a AOL é indicador de musculosidade do animal (CLEMENTINO et al., 2007), estando diretamente relacionado ao relacionado ao rendimento do lombo anterior. 
Rev. Bras. Saúde Prod. Anim., Salvador, v.14, n.3, p.490-507 jul./set., 2013 http://www.rbspa.ufba.br ISSN 15199940

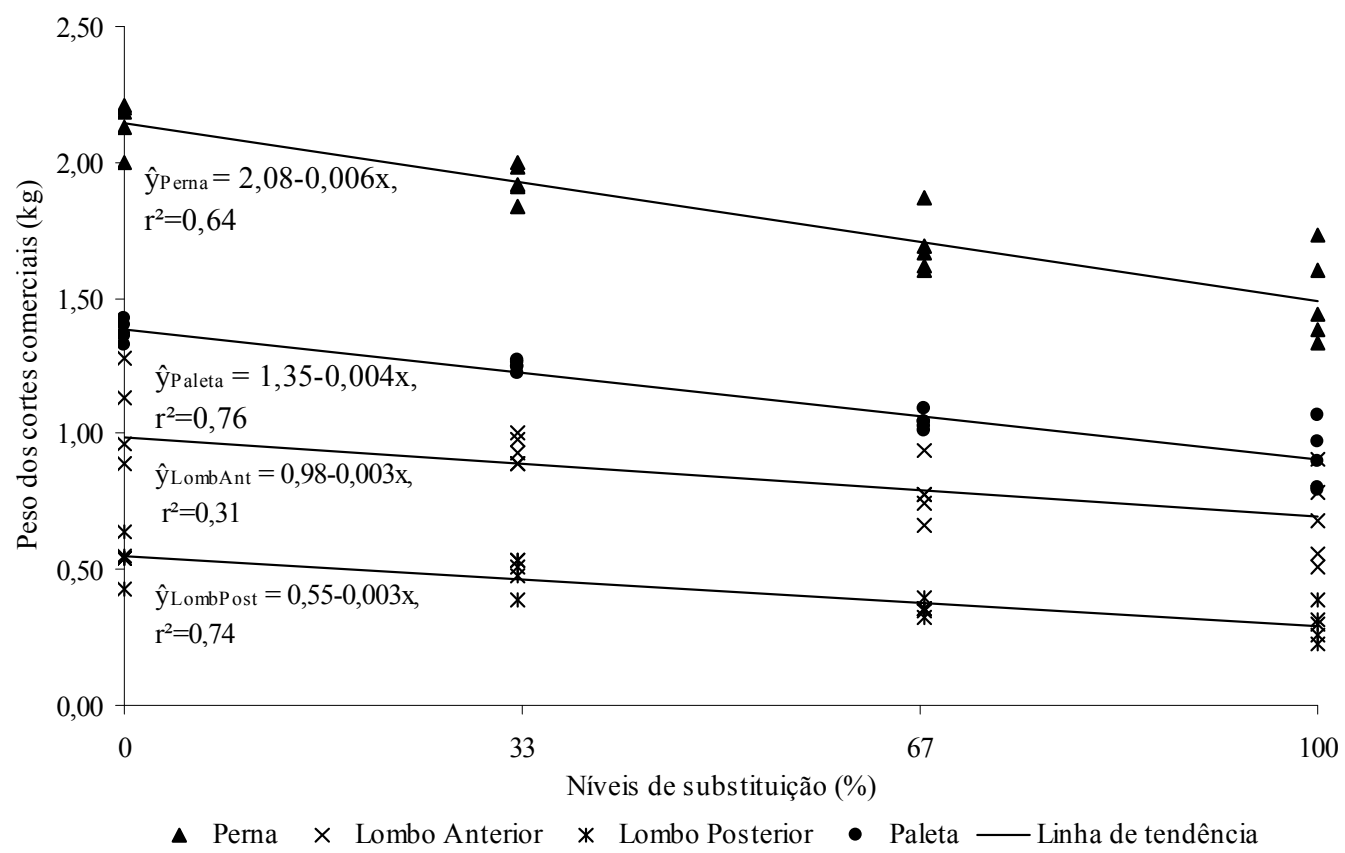

Figura 3. Efeito dos níveis de substituição do feno de tifton- 85 pela casca de mamona sobre o peso dos cortes comerciais (perna, lombo anterior e posterior e paleta) de ovinos. $\hat{y}=$ valores estimados a partir da equação de regressão para cada variável analisada; significativo ao nível de $5 \%$ (*) de probabilidade

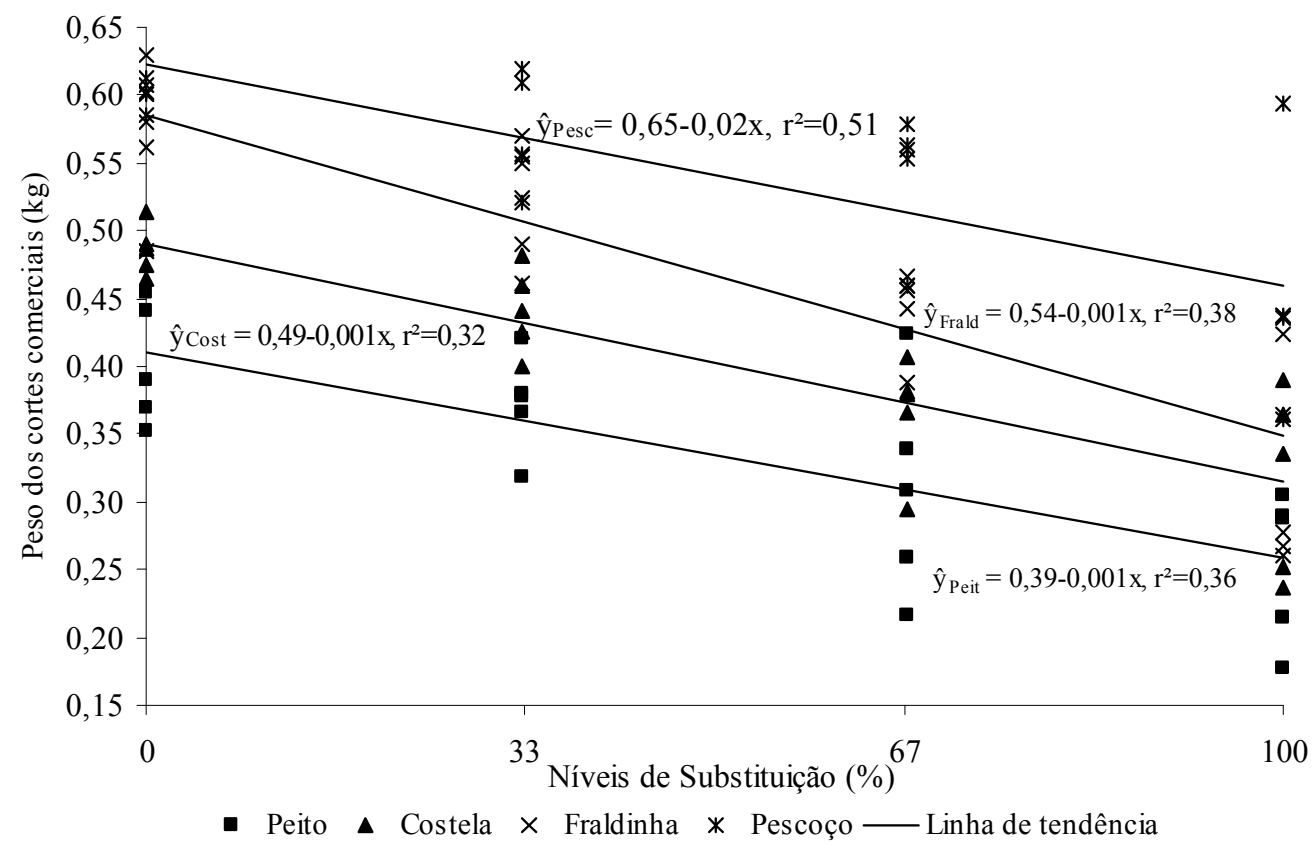

Figura 4. Efeito dos níveis de substituição do feno de tifton-85 pela casca de mamona sobre o peso dos cortes comerciais (peito, costela, fraldinha e pescoço) de ovinos. $\hat{y}=$ valores estimados a partir da equação de regressão para cada variável analisada; significativo ao nível de $5 \%(*)$ de probabilidade 
O rendimento do lombo posterior foi influenciado $(\mathrm{P}<0,05)$ de forma linear decrescente pelos níveis de substituição do FT pela CM, enquanto os rendimentos das demais regiões não apresentaram efeito $(\mathrm{P}>0,05)$ dos níveis de substituição (Figura 5). A perna foi o corte mais pesado e com melhor rendimento percentual, de $30,5 \%$, pois possui maior musculosidade e maior rendimento da parte comestível (SILVA SOBRINHO, 2001).

Considerando o rendimento dos cortes e sua valorização comercial, não foi observado efeito $(\mathrm{P}>0,05)$ dos níveis de substituição do feno de capim-tifton 85 pela casca de mamona sobre os cortes considerados de primeira (pernil + lombo), com média de $51,5 \%$ da carcaça fria, devido à ausência de efeito dos tratamentos sobre o rendimento da perna e do lombo anterior, sendo estes de maior magnitude para a obtenção da variável. De acordo com Zundt et al. (2003), a adequada conformação indica desenvolvimento proporcional das distintas regiões anatômicas que a integram, de modo que as melhores conformações são alcançadas quando as partes de maior valor comercial estão bem pronunciadas.

Para os rendimentos dos cortes de terceira, que incluem costelas, peito, fraldinha e pescoço, não foram observados efeito $(\mathrm{P}>0,05)$ dos níveis de substituição do FT pela $\mathrm{CM}$, com média igual a 29,4\%. Zapata et al. (2001) citam para ovinos Morada Nova da variedade branca, valores entre 32,2 e $32,7 \%$ para o pernil; 19,9 e $21,4 \%$ (paleta) e 10,3 e $11,1 \%$ (lombo), em relação à carcaça fria, sendo próximos aos encontrados no presente estudo para os mesmos cortes.

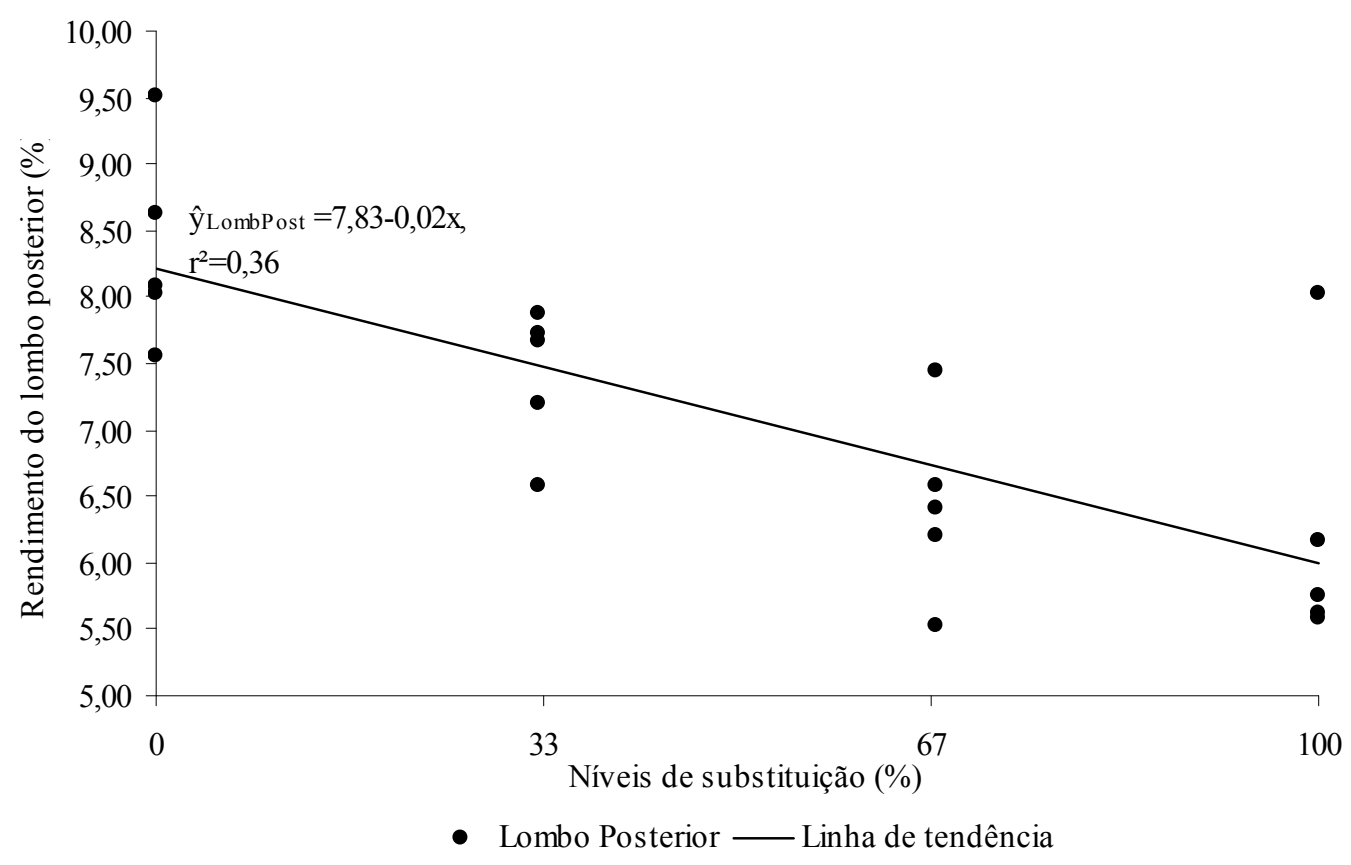

Figura 5. Efeito dos níveis de substituição do feno de tifton- 85 pela casca de mamona sobre o rendimento do lombo posterior de ovinos. $\hat{y}=$ valores estimados a partir da equação de regressão para cada variável analisada; significativo ao nível de $5 \%(*)$ de probabilidade 
Os resultados desta pesquisa revelam, de forma geral, que os cortes de maior importância comercial possuem significativa participação na carcaça, representando mais de 50\% desta, considerando apenas a perna e o lombo (cortes de $1^{\mathrm{a}}$ categoria) e atingindo $70,6 \%$ com a incorporação da paleta, corte de $2^{\mathrm{a}}$ categoria, mas bastante valorizado pelo consumidor e que agrega mais valor ao produto final. Resultados semelhantes aos obtidos neste trabalho foram relatados por Pompeu et al. (2012) ao trabalharem com ovinos mestiços de Morada Nova alimentados com dietas contendo torta de mamona destoxificada em substituição ao farelo de soja.

Para as respostas dos componentes nãocarcaça observou-se efeito $(\mathrm{P}<0,05)$ dos níveis de substituição do feno de capimtifton 85 pela casca de mamona (Figuras 6, 7, 8 e 9), para maioria dos constituintes, com exceção da vesícula biliar, bexiga, nódulos, abomaso, intestino delgado e gordura do coração. Ressalta-se a importância de estudos direcionados sobre os constituintes nãocarcaça, tendo em vista seu alto valor comercial. Estes componentes podem ser aproveitados, sendo que alguns deles servem como alimento para a população humana, como, a cabeça, o fígado, o coração, os rins, o pulmão e o trato digestivo (OSÓRIO et al., 2002). Além disso, também podem ser comercializados e agregar valor ao animal em geral, podendo representar até $40 \%$ do peso corporal dos ovinos.

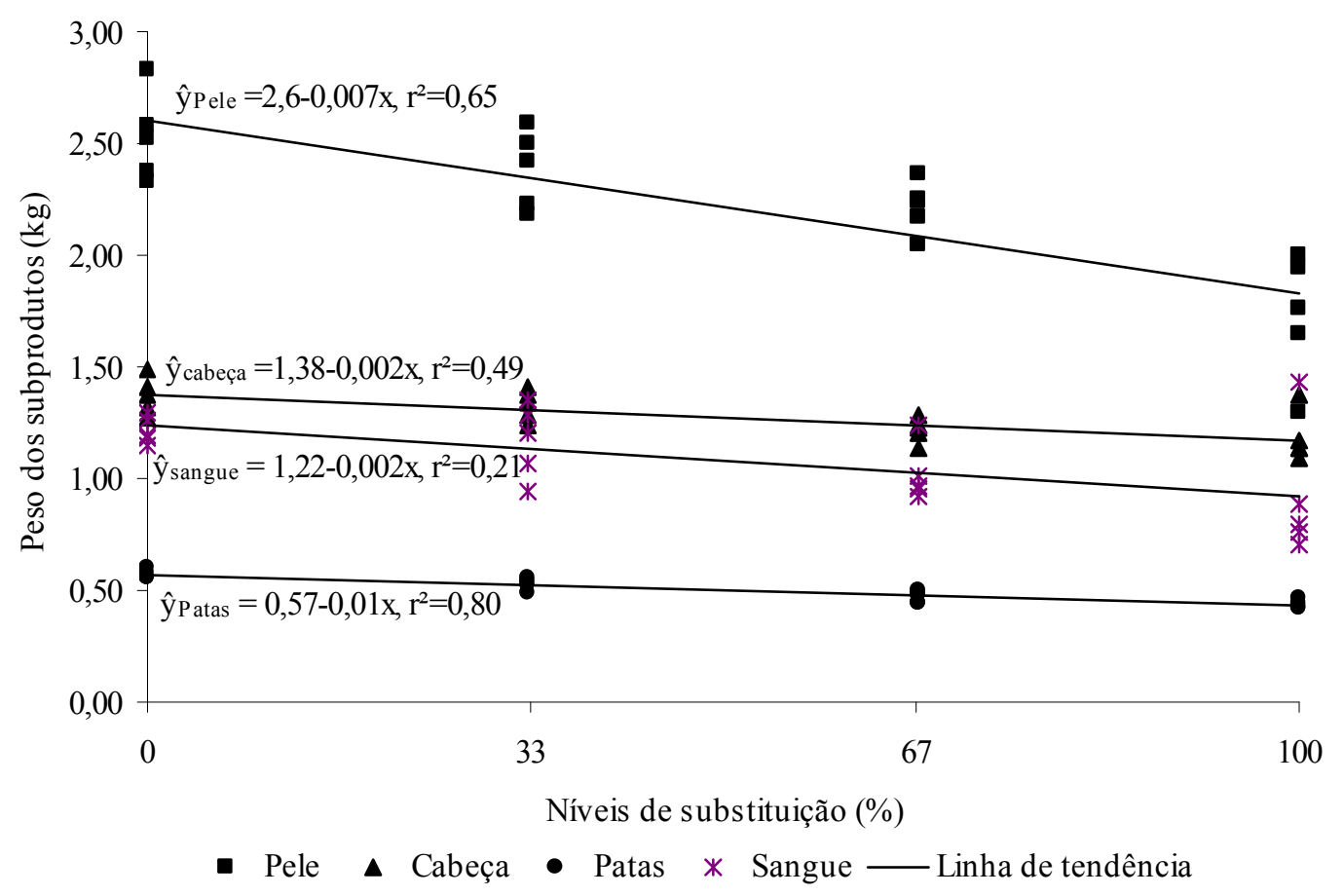

Figura 6. Efeito dos níveis de substituição do feno de tifton- 85 pela casca de mamona sobre o peso dos subprodutos de ovinos. $\hat{\mathrm{y}}=$ valores estimados a partir da equação de regressão para cada variável analisada; significativo ao nível de $5 \%\left(^{*}\right)$ de probabilidade 
Rev. Bras. Saúde Prod. Anim., Salvador, v.14, n.3, p.490-507 jul./set., 2013 http://www.rbspa.ufba.br ISSN 15199940

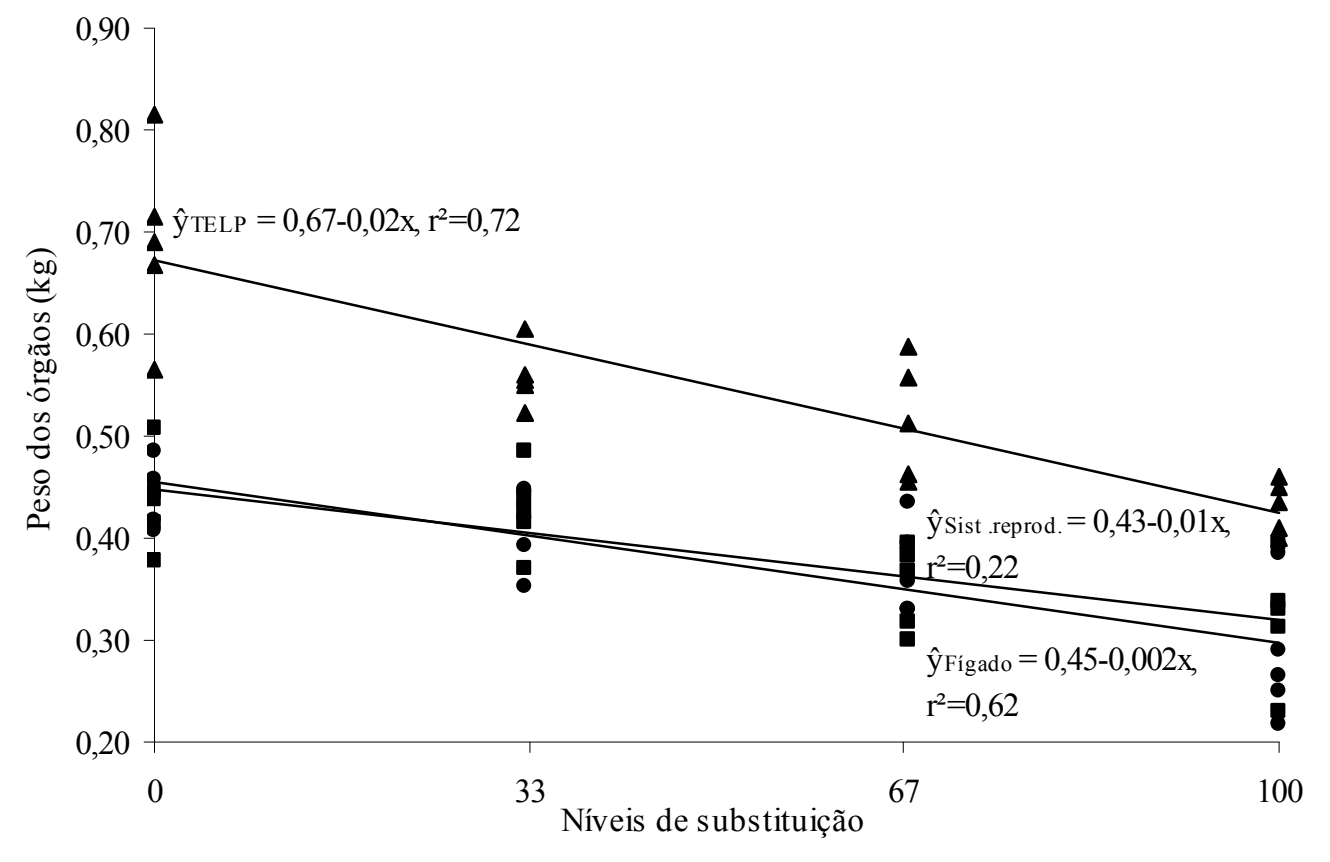

- Sist. Reprodutivo

\ Traquéia/Esôfago/Pulmão/Língua (TELP)

- Fígado — Linha de tendência

Figura 7. Efeito dos níveis de substituição do feno de tifton- 85 pela casca de mamona sobre o peso dos órgãos (sistema reprodutivo, fígado e conjunto traquéia, esôfago, pulmão e língua) de ovinos. $\hat{y}=$ valores estimados a partir da equação de regressão para cada variável analisada; significativo ao nível de $5 \%(*)$ de probabilidade

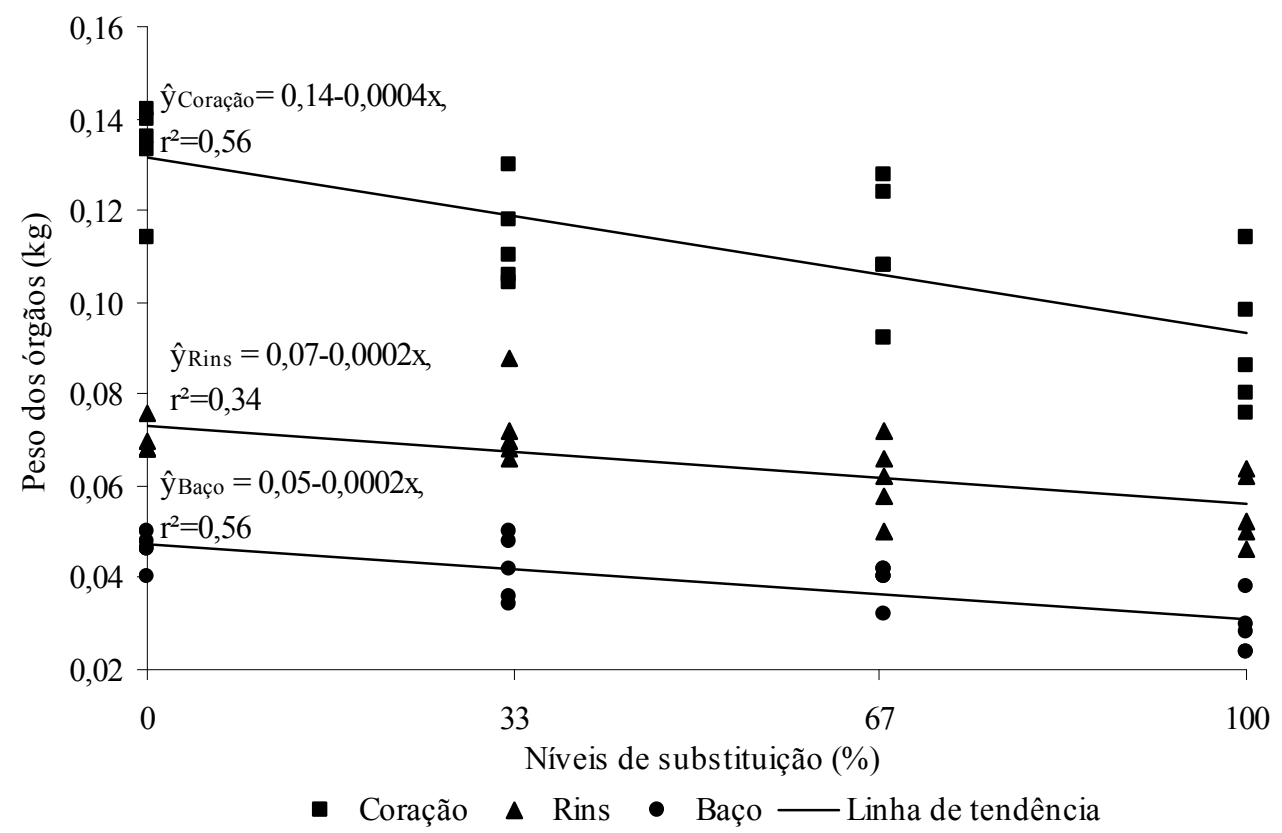

Figura 8. Efeito dos níveis de substituição do feno de tifton-85 pela casca de mamona sobre o peso dos órgãos (coração, rins e baço) de ovinos. $\hat{y}=$ valores estimados a partir da equação de regressão para cada variável analisada; significativo ao nível de 5\% (*) de probabilidade 


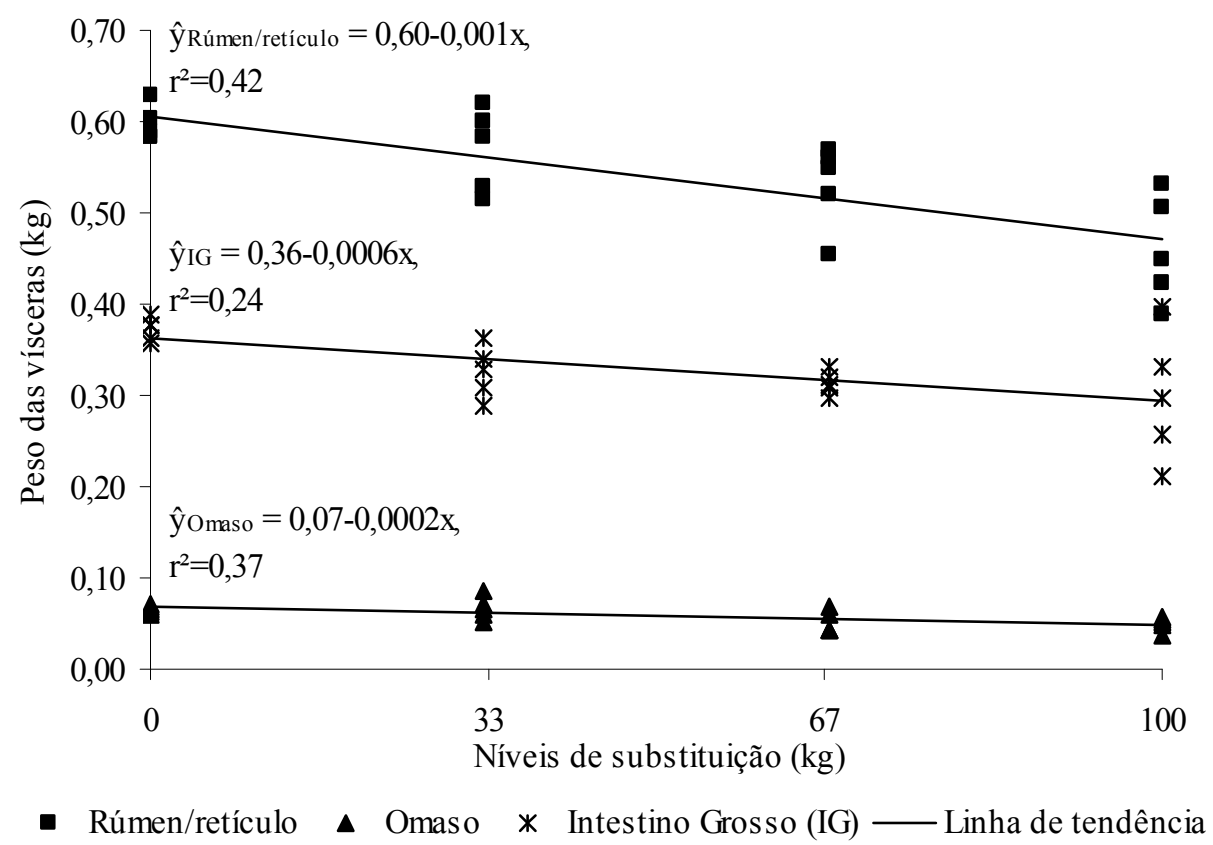

Figura 9. Efeito dos níveis de substituição do feno de tifton-85 pela casca de mamona sobre o peso das vísceras de ovinos. $\hat{y}=$ valores estimados a partir da equação de regressão para cada variável analisada; significativo ao nível de $5 \%(*)$ de probabilidade

As peles com maior peso foram obtidas com as dietas que possuíam menores níveis de casca de mamona na dieta dos animais, com decréscimo de $0,007 \mathrm{~kg}$ para cada $1 \%$ de substituição (Figura 5). $\mathrm{O}$ peso da pele foi o componente nãocarcaça de maior proporção quando comparado aos demais, sendo o mais importante devido ao seu maior preço potencial, que chega a 10 a $20 \%$ do valor do animal (CAMILO et al., 2012; TONETTO et al., 2004), principalmente quando está relacionada à pele de borregos Morada Nova que têm grande valor no mercado internacional. As peles dos animais da raça Morada Nova apresentam, além da espessura, maior quantidade de fibras de colágeno, distribuídas nas camadas reticulares, e uma pequena quantidade de componentes não-estruturais, como glândulas sebáceas, sudoríparas e folículos pilosos (MEDEIROS et al., 2008), características que são bastante valorizadas pela indústria de couro.
Houve efeito linear negativo $(\mathrm{P}>0,05)$ dos níveis crescentes de substituição do FT pela CM na dieta dos animais sobre o peso de cabeça e pés, sendo estimados decréscimos de 0,002 e 0,001 kg para percentual de CM na dieta, estando relacionados ao menor desenvolvimento dos animais decorrente do menor consumo de nutrientes nos tratamentos com maiores níveis de casca de mamona. O peso, em quilogramas, do componente sangue também foi influenciado $(\mathrm{P}>0,05)$ pelos níveis de substituição do FT pela $\mathrm{CM}$ na dieta dos ovinos. Os animais que receberam casca de mamona em até $33 \%$ na dieta tiveram crescimentos favorecidos, o que resultaram em maiores pesos ao abate (Figura 1) e, consequentemente, maior aporte sangüíneo.

$\mathrm{O}$ peso dos órgãos foi influenciado negativamente $(\mathrm{P}>0,05)$ pelos níveis de substituição do feno de tifton-85 pela casca de mamona, com exceção da vesícula biliar (Figuras 7 e 8). Isso pode 
ser explicado pelo menor crescimento dos animais à medida que foi adicionado $\mathrm{CM}$ em substituição ao FT na dieta dos animais, atingindo menor peso corporal ao abate, apresentando menor peso dos órgãos e suportando menores demandas fisiológicas de um peso corporal inferior (GOMES et al., 2012). Ainda, de acordo com Ferreira et al. (2000), embora o coração e os pulmões sejam órgãos que mantêm sua integridade e serem prioritários na utilização de nutrientes, independentemente do nível de alimentação, neste presente trabalho, observa-se influência negativa da casca de mamona sobre o peso desses componentes.

Os pesos da vesícula biliar, da bexiga e dos nódulos não apresentaram efeito $(\mathrm{P}>0,05)$ com a elevação da casca de mamona na dieta dos animais, com médias de $0,02, \quad 0,01$ e $0,03 \mathrm{~kg}$ respectivamente, podendo ser explicado pelo peso desses constituintes serem baixos e de pouca variação.

Os pesos do rúmen/retículo, omaso e intestino grosso foram influenciados pela substituição do FT pela $\mathrm{CM}$ apresentando efeito linear negativo $(\mathrm{P}<0,05)$, com estimativas de 0,001 , 0,0002 e $0,0006 \mathrm{~kg}$ para cada $1 \%$ de substituição (Figura 9). O menor peso do rúmen/retículo e omaso podem estar relacionados ao menor consumo de fibra em detergente neutro pelos animais à medida que foi adicionado CM à dieta (MACITELLI et al., 2005), já que esses componentes têm função de reter o alimento nesses segmentos para ação fermentativa dos microrganismos ruminais. No Nordeste brasileiro, é comum a utilização de vísceras (rúmen, retículo, omaso, abomaso e intestino delgado) e alguns órgãos (pulmões, coração, fígado, baço, rins e língua), além de outros componentes - sangue, omento, diafragma, cabeça e patas para a preparação de pratos tradicionais como o sarapatel, panelada e a buchada (MEDEIROS et al., 2008). O beneficiamento desses órgãos deve ser realizado com intuito de agregar valor ao produto, aumentando as receitas da ovinocultura para que possa se tornar uma atividade rentável, principalmente para o pequeno produtor.

De acordo com Louvandini et al. (2007), órgãos e vísceras possuem distintas velocidades de crescimento durante a vida do animal, quando comparados a outras partes do corpo e pode estar relacionado à composição química dos alimentos, especialmente, ao teor de energia. Apesar disso, a condição semelhante da energia e proteína das rações proporcionou diferenças entre as vísceras e órgãos em decorrência do menor consumo de matéria seca devido à menor aceitabilidade da casca de mamona em relação ao feno de capim-tifton 85 .

Verificou-se efeito linear decrescente $(\mathrm{P}<0,05)$ dos níveis de substituição do FT pela CM sobre as gorduras perirenal, omental e mesentérica, com decréscimos de 0,03, 0,006 e $0,03 \mathrm{~kg}$ para cada $1 \%$ de substituição (Figura 10). Tal fato é decorrente do maior peso ao abate dos animais com menores níveis de casca de mamona na dieta, ocorrendo com isto, maiores acúmulos de gorduras precocemente. As deposições de gordura em ovinos tropicais atuam como reservas energéticas para serem mobilizadas durante o período de escassez de alimentos (MAIOR JÚNIOR et al., 2008; MEDEIROS et al., 2008), contudo não são aproveitadas para o consumo humano (FERREIRA et al., 2000). 
Rev. Bras. Saúde Prod. Anim., Salvador, v.14, n.3, p.490-507 jul./set., 2013 http://www.rbspa.ufba.br ISSN 15199940

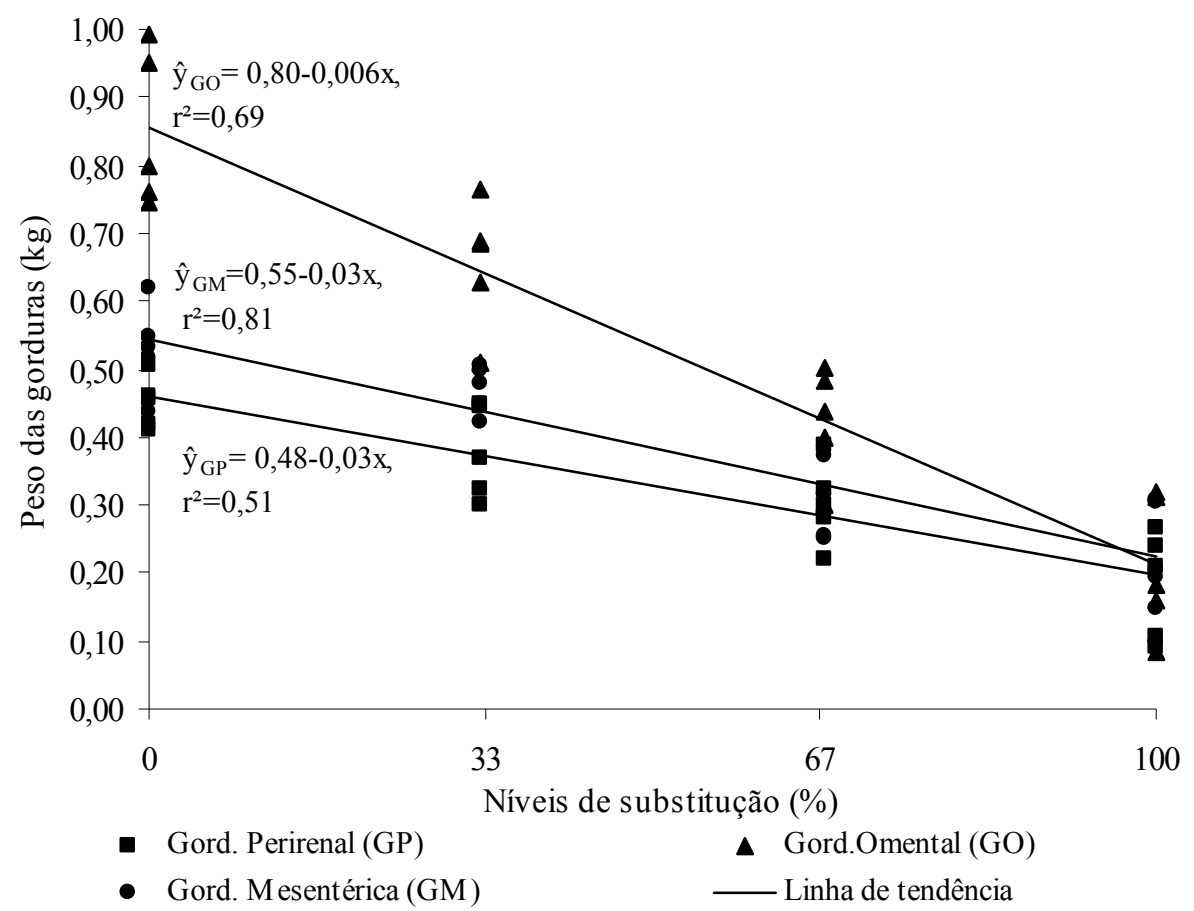

Figura 10. Efeito dos níveis de substituição do feno de tifton-85 pela casca de mamona sobre o peso das gorduras de ovinos. $\hat{y}=$ valores estimados a partir da equação de regressão para cada variável analisada; significativo ao nível de $5 \%\left(^{*}\right)$ de probabilidade

A casca de mamona apresenta potencial para utilização como parte dos ingredientes em dietas para ovinos em terminação, podendo substituir em até $33 \%$ o feno de capim-tifton 85 . A casca de mamona acima de $33 \%$ em substituição ao feno de capim-tifton 85 influencia negativamente nas características das carcaças e nos componentes não-carcaça de ovinos.

\section{REFERÊNCIAS}

ABRAHAMS, P.W.; STEIGMAJER, J. Soil ingestion by sheep grazing the metal enriched flooding soils of midwales. Environmental Geochemistry and Health, v.25, n.1, p.17-24, 2003.

AGRICULTURAL AND FOOD RESEARCH COUNCIL - AFRC. Energy and protein requirements of ruminants. Wallingford: $\mathrm{CAB}$ International, 1993. 175p.

ASSOCIATION OF OFFICIAL ANALYTICAL CHEMISTRY AOAC. Official methods of analysis. 16.ed. Arlington: AOAC International, 1995. 1025p.

CAMILO, D.A.; PEREIRA, E.S.; PIMENTEL, P.G.; COSTA, M.R.G.F.; MIZUBUTI, I.Y.; RIBEIRO, E.L.A.; CAMPOS, A.C.N.; PINTO, A.P.; MORENO, G.M.B. Peso e rendimento dos componentes não-carcaça de ovinos Morada Nova alimentados com diferentes níveis de energia metabolizável. Semina: Ciências

Agrárias, v.33, n.6, p.2429-2440, 2012.

CLEMENTINO, R.H.; SOUSA, W.H.; MEDEIROS, A.N.; CUNHA, M.G.G.; GONZAGA NETO, S.; CARVALHO, F.F.R.; CAVALCANTE, M.A.B. 
Rev. Bras. Saúde Prod. Anim., Salvador, v.14, n.3, p.490-507 jul./set., 2013 http://www.rbspa.ufba.br ISSN 15199940

Influência dos níveis de concentrado sobre os cortes comerciais, os constituintes não-carcaça e os componentes da perna de cordeiros confinados. Revista Brasileira de

Zootecnia, v.36, n.3, p.681-688, 2007.

FERREIRA, M.A.; VALADARES FILHO, S.C.; MUNIS, E.B.; VERAS, A.S.C. Características das carcaças, biometria do trato gastrintestinal, tamanho dos órgãos internos e conteúdo gastrintestinal de bovinos F1 Simental $x$ Nelore alimentados com dietas contendo vários níveis de concentrado. Revista Brasileira de Zootecnia, v.29, n.4, p.1174-1182, 2000.

FRESCURA, R.B.M.; PIRES, C.C.; SILVA, J.H.S.; MÜLLER, L.; CARDOSO A.; KIPPERT, C.J.; PERES NETO, D.; SILVEIRA, C.D. da; ALEBRANTE, L.; THOMAS, L. Avaliação da proporção dos cortes da carcaça, características da carne e avaliação dos componentes do peso vivo de cordeiros. Revista Brasileira de Zootecnia, v.34, n.4, p.167-174, 2005.

GARCIA, C.A. Avaliação de resíduo de panificação "biscoito" na alimentação de ovinos e nas características quantitativas e qualitativas da carcaça. 1998. 79p. Dissertação (Mestrado em Zootecnia) Universidade Estadual Paulista, Jaboticabal.

GATTY, R. Anatomia dos animais domésticos. Rio de Janeiro: Guanabara, 1986.

GIRÃO, R.N. Recomendações técnicas para criação de ovinos deslanados. Teresina, PI: Embrapa/Meio-Norte, 1997. p75. (Circular Técnica, 17).
GOMES, F.H.T.; CÂNDIDO, M.J.D.; CARNEIRO, M.S.S.; FURTADO, R.N.; PEREIRA, E.S.; BOMFIM, M.A.D.; SOMBRA, W.A.; BERNARDES, D.F.V. Características de carcaça em ovinos alimentados com rações contendo torta de mamona.

Revista Brasileira de Saúde e Produção Animal [online], v.13, n.1, p.283-295, 2012.

GONZAGA NETO, S.; SILVA SOBRINHO, A.G.; RESENDE, K.T.; ZEOLA, N.M.B.L.; SILVA, A.M.A.; MARQUES, C.A.T.; LEÃO, A.G. Composição corporal e exigências nutricionais de proteína e energia para cordeiros Morada Nova. Revista Brasileira de Zootecnia, v.34, n.6, p.2446-2456, 2005 (supl.).

LOUVANDINI, H; NUNES, G.A; GARCIA, J.A.S.; McMANUS, C.; COSTA, D.M.; ARAÚJO, S.C.

Desempenho, características de carcaça e constituintes corporais de ovinos Santa Inês alimentados com farelo de girassol em substituição ao farelo de soja na dieta. Revista Brasileira de Zootecnia, v.36, n.3, p.603-609, 2007.

MACITELLI, F.; BERCHIELLI, T.T.; SILVEIRA, R.N.; ANDRADE, P.; LOPES, A.D.; SATO, K.J.; BARBOSA, J.C. Biometria da Carcaça e Peso de Vísceras e de Órgãos Internos de Bovinos Mestiços Alimentados com Diferentes Volumosos e Fontes Protéicas. Revista Brasileira de Zootecnia, v.34, n.5, p.1751-1762, 2005.

MAIOR JÚNIOR, R.J.S.; CARVALHO, F.F.R.; BATISTA, A.M.V.; VASCONCELOS, R.M.J.; SILVA, R.C.B.; FIGUEIREDO, M.A.S. Rendimento e características dos componentes não-carcaça de ovinos alimentados com rações baseadas em 
Rev. Bras. Saúde Prod. Anim., Salvador, v.14, n.3, p.490-507 jul./set., 2013 http://www.rbspa.ufba.br ISSN 15199940

cana -de-açúcar e uréia. Revista

Brasileira de Saúde e Produção

Animal [online], v.9, n.3, p.507-515, 2008.

MATTOS, C.W.; CARVALHO, F.F.R.; DUTRA JUNIOR, W.M.; VERAS, A.S.C.; BATISTA, A.M.V.; ALVES, K.S.; RIBEIRO, V.L.; SILVA, M.J.M.S.; MEDEIROS, G.R.; VASCONCELOS, R.M.J.; ARAUJO, A.O.; MIRANDA, S.B. Características de carcaça e dos componentes não-carcaça de cabritos Moxotó e Canindé submetidos a dois níveis de alimentação. Revista Brasileira de Zootecnia, v.35, n.5, p.2125-2134, 2006.

MEDEIROS, G.R.; CARVALHO, F.F.R.; FERREIRA, M.A.; ALVES, K.S.; MATTOS, C.W.; SARAIVA, T.A.; NASCIMENTO, J.F. Efeito dos níveis de concentrado sobre os componentes nãocarcaça de ovinos Morada Nova em confinamento. Revista Brasileira de Zootecnia, v.37, n.6, p.1063-1071, 2008.

MONTE, A.L.S.; VASCONCELOS, P.M.; CORREIA, L.S.; FARIAS, M.D P.; SELAIVE-VILLARROEL, A.B.; OLIVEIRA, A.N. Composição centesimal e mineral da carne de cabritos mestiços. Higiene Alimentar, v.23, p.134-137, 2009.

MORENO, G.M.B.; SILVA SOBRINHO, A.G.; LEÃO, A.G.; LOUREIRO, C.M.B.; PEREZ, H.L. Rendimentos de carcaça, composição tecidual e musculosidade da perna de cordeiros alimentados com silagem de milho ou cana-de-açúcar em dois níveis de concentrado. Arquivo Brasileiro de Medicina Veterinária e Zootecnia, v.62, n.3, p.686-695, 2010.

MOSHKIN, V.A. Castor. New Delhi: Amerind, 1986. 315p.
OLIVEIRA, A.S.; CAMPOS, J.M.S.; OLIVEIRA, M.R.C.; BRITO, A.F.; VALADARES FILHO, S.C.; DETMANN, E.; VALADARES, R.F.D.; SOUZA, S.M.; MACHADO, O.L.T. Nutrient digestibility, nitrogen metabolism and hepatic function of sheep fed diets containing solvent or expeller castor seed meal treated with calcium hydroxide. Animal Feed Science and Technology, v.158, n.1, p.15-28, 2010.

OSÓRIO, J.C.; OSÓRIO, M.T.; OLIVEIR A, N.M.; SIEWERDT, L. Qualidade, morfologia e avaliação de carcaças. Pelotas: Universidade Federal de Pelotas, 2002. 194p.

POMPEU, R.C.F.F.; CÂNDIDO, M.J.D.; PEREIRA, E.S.; BOMFIM, M.A.D.; CARNEIRO, M.S.S.; ROGÉRIO, M.C.P.; SOMBRA, W.A.; LOPES, M.N. Desempenho produtivo e características de carcaça de ovinos em confinamento alimentados com rações contendo torta de mamona destoxificada em substituição ao farelo de soja.

Revista Brasileira de Zootecnia, v.41, n.3, p.726-733, 2012.

SANTOS, S.F., BOMFIM, M.A.D.; CÂNDIDO, M.J.D.; SILVA, M.M.C.; PEREIRA, L.P.S.; SOUZA NETO, M.A.; GARRUTI, D.S.; SEVERINO, L.S. Efeito da casca de mamona sobre a produção, composição e ácidos graxos do leite de cabra. Archivos de Zootecnia, v.60, n.229, p.113-122, 2011.

SANTOS, V.C.; EZEQUIEL, M.J.B.; PINHEIRO, R.S.B.; BARBOSA, J.C.; GALATI, R.L. Características de carcaça de cordeiros alimentados com grãos e subprodutos da canola. Acta Scientiarum. Animal Sciences, v.31, n.4, p.389-395, 2009. 
Rev. Bras. Saúde Prod. Anim., Salvador, v.14, n.3, p.490-507 jul./set., 2013 http://www.rbspa.ufba.br ISSN 15199940

SAS Institute. SAS system for windows. Version 9.1. Cary, 2003.

SEVERINO, L.S. O que sabemos sobre a torta de mamona. Campina Grande: Embrapa Algodão, 2005. 31p. (Documento, 134).

SILVA, L.F.; PIRES, C.C. Avaliações quantitativas das proporções de osso, músculo e gordura da carcaça em ovinos. Revista Brasileira de Zootecnia, v.29, n.4, p.1253-1260, 2000 .

SILVA SOBRINHO, A.G. Aspectos quantitativos e qualitativos da produção de carne ovina. In: MATTOS, W.R.S.; FARIA, V.P.; SILVA, S.C.; NUSSIO, L.G.; MOURA, J.C. de (Eds.). A produção animal na visão dos brasileiros. Piracicaba: Fundação de Estudos Agrários, 2001. p.425-460.

SILVA SOBRINHO, A.G. Body composition and characteristics of carcass from lambs of different genotypes and ages at slaughter. 1999. 54p. Thesis (Post-Doctorate in Sheep Meat Production) - Massey University, Palmerston North.

TONETTO, C.J.; PIRES, C.C.; MULLER, L.; ROCHA, M.G.; SILVA, J.H.S.; FRESCURSA, R.B.M.; KIPPERT, C.J. Rendimentos de cortes da carcaça, características da carne e componentes do peso vivo em cordeiros terminados em três sistemas de alimentação. Revista Brasileira de Zootecnia, v.33, n.1, p.234-241, 2004.

Van SOEST, P.J.; ROBERTSON, J.B.; LEWIS, B.A. Methods for dietary fiber, neutral detergent fiber, and nonstarch polysaccharides in relation to animal nutrition. Journal of Dairy Science, v.74, p.3583-3597, 1991.
VIEIRA, M.M.M.; CÂNDIDO, M.J.D.; BOMFIM, M.A.D.; SEVERINO, L.S.; ZAPATA, J.F.F.; BESERRA, L.T.; MENESES, A.J.G.; FERNANDES, J.P.B. Características da carcaça e dos componentes não-carcaça em ovinos alimentados com rações à base de farelo de mamona. Revista Brasileira de Saúde e Produção Animal [online], v.11, n.1, p.140,149, 2010.

YAMAMOTO, S.M.; MACEDO, F.A.F.; MEXIA, A.A.; ZUNDT, M.; SAKAGUTI, E.S.; ROCHA, G.B.L.; REGAÇONI, K.C.T.E.; MACEDO, R.M.G. Rendimento dos cortes e não componentes da carcaça de cordeiros terminados com dietas contendo diferentes fontes de óleo vegetal. Ciência Rural, v.34, n.6, p.1909-1913, 2004.

ZAPATA, J.FF.; SEABRA, L.M.A.J.; NOGUEIRA, C.M; BEZERRA, L.C.; BESERRA, F.J. Características de carcaça de pequenos ruminantes do Nordeste do Brasil. Revista Ciência Animal, v.11, n.2, p.79-86, 2001.

ZUNDT, M.; MACEDO, F.A.F.; MARTINS, E.N.; MEXIA, A.A.; NIETO, L. M.; YAMAMOTO, S.M.; MACEDO, R.M.G. Características de carcaça de cordeiros terminados em confinamento, com dietas contendo diferentes níveis protéicos.Ciência Rural, v.33, n.3, p.565-571, 2003.

Data de recebimento: 05/02/2013 Data de aprovação: 13/09/2013 